IJPPM

57,5 Accepted March 2008
Received March 2008

\section{REFLECTIVE PRACTICE Can Six Sigma be effectively implemented in SMEs?}

\author{
Jiju Antony \\ Centre for Research in Six Sigma and Process Excellence, \\ Strathclyde Institute for Operations Management, University of Strathclyde, \\ Glasgow, UK
}

\begin{abstract}
Purpose - This paper aims to present the viewpoints from a number of leading practitioners and academics on the subject "Can Six Sigma be effectively deployed in small and medium-sized enterprises (SMEs)?".

Design/methodology/approach - A number of academics and practitioners were interviewed by the author to collate their opinions and views on the above subject.

Findings - The results of the study clearly indicate that Six Sigma is equally applicable to both large corporations and small companies. In fact, the results are quicker and much more visible in smaller companies than in larger corporations.

Originality/value - This paper provides an excellent resource for those people who believe that Six Sigma is primarily meant for large companies. It also makes an attempt to remove one of the common myths of Six Sigma.
\end{abstract}

Keywords Quality management, Six sigma, Process management, Performance management

Paper type Viewpoint

Six Sigma is a well-established approach that seeks to identify and eliminate defects, mistakes or failures in business processes or systems by focusing on those process performance characteristics that are of critical importance to customers. With more than two decades of successful implementation of Six Sigma methodologies at major corporations, the benefits of Six Sigma are well documented. Although Six Sigma has been implemented with success in many large corporations, there is still less documented evidence of its implementation in smaller organisations. Moreover, in the author's experience as a researcher and quality management consultant, SMEs are still not convinced that Six Sigma can be effectively implemented within SMEs. This article attempts to address this issue - can Six Sigma can be effectively implemented in SMEs? One of the common myths of Six Sigma that has emerged over the last few years is that it is just applicable to large corporations with immense resources and budget. The purpose of this article is to test this myth and to show that a Six Sigma-based business strategy is applicable to all kinds of businesses irrespective of the size and type of industry; manufacturing or service.

This viewpoint article aims to present the results of a study carried out by the

International Journal of Productivity and Performance Management

Vol. 57 No. 5,2008

pp. $420-423$

(C) Emerald Group Publishing Limited 1741-0401

DOI $10.1108 / 17410400810881863$ author in the form of a panel discussion on the topic - "Can Six Sigma be effectively implemented in small and medium-sized enterprises (SMEs)"? The panel consisted of leading practitioners and academics who are familiar with the Six Sigma topic as well as general quality management/engineering fields. 
Dr Ronald Snee - Principal of Tunnell Consulting, USA

SMEs can, and have, effectively applied Six Sigma. Companies with 1 to 5 billion dollars in sales typically get 2 to 4 per cent of sales to the bottom-line each year using Six Sigma. There are issues for SMEs such as:

- difficult to stay focused due to many distractions within the business;

- difficult to dedicate six sigma black belts full time to executing projects;

- employees perform many different functions unlike larger organizations;

- senior management leadership is important; and

- can start by focusing on "low hanging fruits".

An effective strategy is to identify project purpose, payback in hard cash savings and required resources (people time and expenses) and then decide if it makes business sense to employ the Six Sigma strategy.

\section{Dr Roger Hoerl - GE Global Research, USA}

There is nothing inherent in Six Sigma that makes it more suitable for large companies. We tend to think of Six Sigma for large organisations, because the media tends to focus on GEs, 3Ms, and other Fortune 100 companies' success. Six Sigma can have a significant impact on SMEs. For example, the financial results from implementation of Six Sigma at W.R. Grace were actually more impressive than GE's results on a percent of revenue basis. The greatest barrier to implementation of Six Sigma in small companies to date has been the way major Six Sigma training providers have structured their offerings. These offerings often require large up-front payments to cover the use of copyrighted training materials. More recently, as more and more sets of deployment guides and training materials have become available, the pricing structures have begun to change. Beyond that, there are some unique issues at small companies, such as the fact that many employees wear multiple "hats", i.e. have diverse accountabilities, making it harder to dedicate Master Black Belts (MBBs) or Black Belts (BBs). However, there are unique issues in healthcare, in financial services and even in manufacturing versus discrete manufacturing, so we should not let the challenges prevent us from moving forward.

\section{Mr Thomas Pyzdek - Pyzdek Consulting, USA}

There are two facets of Six Sigma: the approach and the infrastructure. The approach of leading through Six Sigma can be adapted by leaders in any sized firm. Very small businesses will have difficulty justifying full time MBBs and BBs and will rely primarily on Green Belts (GBs) coached by experts outside of the company. Medium-sized firms can gain maximum leverage by having experienced and highly trained MBBs or BBs coaching ten to $20 \mathrm{GBs}$ each.

\section{Professor T N Hoh - National University of Singapore, Singapore}

First of all, get rid of the hype - a Six Sigma project will not necessarily save upwards of $\$ 200,000$ per project. It is advisable right from the start to give all CEOs a realistic view of what Six Sigma is, and what it is not. Second, there is no scientific basis that a person must go through at least four months of intensive training (and paying heaps of fees for training) before Six Sigma can be introduced. SMEs may first invite Six Sigma experts to look into their respective operations and potential areas of applications.
Can Six Sigma be effectively implemented? 
IJPPM

57,5

422
Tailoring training programs to suit the needs of a specific organisation: for example, certain projects can actually be heavy on "DMA" and very thin on "IC", so there is no reason to force the whole works down the throat of everyone, at least initially.

\section{Professor Rick Edgeman - University of Idaho, USA}

SMEs are commonly confronted by limited human capital, especially in terms of "specialisations" and training budgets. Moreover, once trained, a Six Sigma Black Belt is in sufficient demand that they may be enticed by a larger company with a more notable reputation or better salary/benefits. In the context of SMEs, be very judicious in which projects are selected for Six Sigma application. It is important to ensure that early applications of Six Sigma methodology have a very high probability of success.

\section{Dr Matthew Hu - American Supplier Institute, USA}

Small companies are very good at finding reasons "why it cannot work here"? But a quality problem is a quality problem. Variation is variation. Waste is waste. An unhappy customer is an unhappy customer. The size of the company really does not change these facts.

Six Sigma is very appropriate for smaller companies too. The Six Sigma process works well in a billion dollar corporation as well as $\$ 25$ million privately held companies. In fact, in my experience, the results are usually quicker and more visible in smaller companies.

\section{Professor Amitava Mitra - Auburn University, USA}

SMEs may have a limited budget for Six Sigma training. While the project leader must be trained in the key concepts and Six Sigma methodology, it is highly desirable the team members have some exposure as well. If such training is not possible for team members, due to budget restrictions, the concept of benchmarking could be important. Best practices for certain processes, not necessarily in the same industry, could be explored and their adoption to the organisation could be studied.

Employee motivation is another avenue to promote creativity and enthusiasm that leads to quality improvement. If top management makes a commitment to seek suggestions of ideas and implement some of those that are feasible, within the resource constraints of the company, it will provide a boost to the morale of the employees. This will make employees feel as part of the organisation and provide them with ownership of the process.

\section{Mr Larry Smith - Past Vice President of Design and Innovation, Juran Institute, USA}

Since large companies tend to be organised into small and medium sized departments and operations, I suspect that what is done in large companies also applies to SMEs. When I worked for Ford, we started Six Sigma within one department and obtained support from outside the company. As knowledge and experience grows in an organisation, support will come from resources inside the company rather than outside. The implementation of Six Sigma will create efficiencies - some of which may be used to provide these resources for longer-term support and growth.

\section{Mr Alan Harrison - Weir Pumps, UK}

I believe that many SMEs can collect low hanging improvements by applying Deming's PDCA improvement cycle and Six Sigma way of thinking at its basic 
level (for example, at Green Belt level). Having a pragmatic approach, Six Sigma can help:

- define the need to improve and share - communicate and drive positive dissatisfaction with current business performance, based on facts;

- measure and analyse opportunities for the project selection - create a pull system for improvements, where projects are pulled from and defined by business/customers' needs;

- drive by personal inspiration - improvements driven by business process owners, who need to have ability to create and share vision and inspirational passion and can provide necessary resources to improve and sustain; and

- make it happen - promote that the smallest action is larger than the biggest intention.

\section{Dr Lynne Hare - Kraft Foods Research, USA}

Scale should not really enter into a decision to adopt a Six Sigma management philosophy. All companies, large and small share many common features and problems. Large companies, because of scale, may reap higher financial gains as a result of a given breakthrough, but this should not be taken to suggest that small companies would not benefit tremendously from the implementation of Six Sigma business strategy.

\section{Professor Jiju Antony - Centre for Research in Six Sigma and Process Excellence - University of Strathclyde, UK}

In SMEs, the senior management team (SMT) must be visibly supportive of every aspect of a Six Sigma initiative. They must demonstrate by their active participation, involvement and actions that such support is more than lip service. Six Sigma is about overall business strategy, culture and change, and the small companies embarking on Six Sigma initiative need to build all of this into a sound corporate strategy plan.

As small companies are more agile, it is much easier to buy in management support and commitment, as opposed to large organisations. The education and training component is much harder for smaller companies. Moreover, small companies do not have the slack to free up talented people to engage in training, followed by the execution of Six Sigma projects. These people are crucial to the day-to-day operations and problem solving within the company. Academic institutions should help SMEs to meet their customer or stakeholder needs and assist them in creating value for their key customers. This will ensure development of a stable, long-term and cost-effective relationship between the organisation and academic institution. The Centre for Research in Six Sigma and Process Excellence (CRISSPE) at the University of Strathclyde provides a number of seminars and workshops on Six Sigma topics to local SMEs. These enable them to share their experience of fundamental barriers and problems in the introduction of the Six Sigma programme.

\section{Corresponding author}

Jiju Antony can be contacted at: jiju.antony@strath.ac.uk

\footnotetext{
To purchase reprints of this article please e-mail: reprints@emeraldinsight.com
} Or visit our web site for further details: www.emeraldinsight.com/reprints
Can Six Sigma be effectively implemented? 